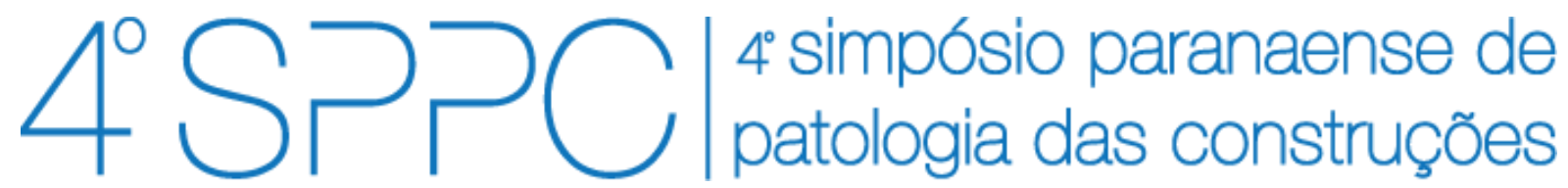

ISSN 2526-7248 artigo n. 4SPPC141, pp. 370-380, 2019

\title{
Ataque por íons cloreto em argamassas reforçadas com fibras de aço: influência do tempo de exposição e da abertura de fissura
}

\author{
Nunes, Ana Carolina Moreno 1; Pieralisi, Ricardo 2; Bragança, Mariana D’Orey \\ Gaivão Portella ${ }^{3}$ \\ ${ }^{1}$ Mestranda, Universidade Federal do Paraná, anacarolnunes.96@gmail.com \\ 2 Professor Doutor, Universidade Federal do Paraná, ricpieralisi@gmail.com \\ 3 Pesquisadora Doutora, Lactec, mariana.portella@lactec.org.br
}

Resumo: Por não ser possível garantir o cobrimento do aço em aplicações com a incorporação de fibras questionamentos em relação à durabilidade do material são levantados. Nesse sentido, o objetivo deste trabalho foi avaliar a influência do ataque por íons cloreto na resistência à tração na flexão de argamassas reforçadas com fibras de aço. Para isso, os corpos de prova foram dividos em três grupos, sendo eles: (1) sem fissura; (2) abertura de primeira fissura; e (3) fissura de carga máxima. 0 ensaio de tração na flexão foi realizado nas amostras dos grupos 2 e 3 antes do período de exposição. Todos os corpos de prova foram submetidos ao processo de intemperismo artificial em câmara de névoa salina, com ciclos de molhagem e secagem, durante as idades de 28, 56, 112 e 224 dias. Após, realizou-se o ensaio de tração na flexão novamente, para verificação da influência do ataque por cloretos na resistência mecânica pós-pico em todas as amostras. Os resultados demonstraram que houve ganho inicial de resistência, que pode ser decorrente da aderência entre os produtos de corrosão e a matriz cimentícia. Porém, após 112 ciclos de exposição houve decréscimo da resistência pós-pico, fato que pode estar relacionado à perda de seção resistente das fibras de aço.

Palavras-chave: Argamassa reforçada, fibra de aço, ataque por cloretos.

Abstract: Because it is not possible to guarantee the covering of steel in applications with the incorporation of fibers questions regarding the durability of the material are raised. The objective of this work was to evaluate the influence of the chloride ion attack on the post-peak behavior of steel fiber reinforced mortars induced by a 3-point bending test. In this sense, the test specimens were divided into three groups: (1) without crack; (2) first crack opening; and (3) crack at tensile peak. In order to achieve the necessary crack open, the 3-point bending test was performed on the specimens of the groups 2 and 3 . All the specimens of the groups were submitted to the artificial weathering process in a saline mist chamber with wetting and drying cycles, during the period of 28,56, 112 and 224 days. After, the 3-point bending test was performed to verify the influence of the chloride attack on the post-peak tensile strength behavior. It was observed that there is an increase of tensile strength in the post-peak, related to the adhesion between the corrosion products and the cementitious matrix. However, after 112 cycles of exposure, there was a decrease in the post-peak tensile strength. The latter is related to the loss of a strength section of the steel fibers.

Keywords: Reinforced mortar, steel fiber, chloride attack. 
NUNES, A. C. M.; PIERALISI, R.; BRAGANÇA, M. O. G. P., ATAQUE POR ÍONS CLORETO EM ARGAMASSAS REFORÇADAS COM FIBRAS DE AÇO: INFLUÊNCIA DO TEMPO DE EXPOSIÇÃO E DA ABERTURA DE FISSURA. $4^{\circ}$ Simpósio Paranaense de Patologia das Construções (40 SPPC), artigo 4SPPC141, pp. 370 - 380, 2019. DOI: 10.4322/2526-7248.059

\section{Introdução}

O Concreto Reforçado com Fibras de Aço (CRFA) foi desenvolvido como uma alternativa ao concreto armado, e constitui-se em um material no qual as fibras atuam sobre as tensões de tração, promovendo ductilidade para o elemento estrutural [1]. Os primeiros estudos sobre o uso de fibras de aço para a fabricação de CRFA datam da década de 1960. Desde então, pesquisas foram realizadas para entender com maior profundidade o comportamento e as propriedades mecânicas deste material $[2,3]$.

As fibras podem ser incorporadas à mistura juntamente com as demais partes constituintes do compósito, como agregados e cimento. Essa prática facilita a execução dos elementos estruturais, visto que atividades como montagem, amarração e instalação de barras de armaduras podem ser reduzidas ou até suprimidas pela presença das fibras. No cenário nacional, as fibras são amplamente utilizadas em pavimentos industriais, ou seja, em estruturas com baixo grau de solicitação. Porém, existem outras aplicações nas quais o uso de fibras pode ser benéfico, como em concreto projetado para revestimento de túneis, peças préfabricadas e em regiões de instabilidade, devido a ocorrência de abalos sísmicos frequentes [4].

Entretanto, sabe-se que o aço é suscetível à corrosão quando exposto ao ataque de agentes agressivos, como os íons cloretos e sulfatos, culminando na perda de seção resistente e, consequentemente, na diminuição da vida útil da edificação. Deste modo, no CRFA, propriedades como a cinética de corrosão das fibras dentro da matriz cimentícia e a perda de resistência do compósito, devido ao ataque de agentes agressivos, são aspectos importantes e necessitam ser considerados [5,6].

Ao tratar-se de estruturas expostas a ambientes agressivos, a presença de fissuras pode facilitar o transporte de agentes deletérios para o interior do compósito. Nesse sentido, sabe-se que a corrosão decorrente do ataque por cloretos em estruturas de concreto reforçadas com elementos de aço é uma das principais ameaças a durabilidade do material. Isso porque após o início das reações de corrosão, há a perda gradativa das propriedades resistentes do aço e, consequentemente, do concreto, culminando, em casos mais severos, na condenação da estrutura e fim de sua vida útil [5]. As pesquisas convergem para a verificação do melhor desempenho do CRFA não fissurado em comparação ao reforço convencional, em situações de exposição à ambientes salinos. No entanto, há divergências sobre o comportamento do CRFA fissurado quando submetido à ação de íons $\mathrm{Cl}^{-}$. Isso porque a cinética da corrosão nas fibras é diferenciada e requer análises detalhadas para verificação de sua influência na resistência à tração e comportamento pós-fissuração do compósito [6].

Diante disso, o objetivo deste artigo é avaliar a influência do ataque de íons cloreto na resistência mecânica à tração de argamassa reforçada com fibras de aço. Essa avaliação foi feita por meio da análise dos resultados de resistência à tração na flexão e do acompanhamento fotográfico do aparecimento e aumento de manchas superficiais de corrosão nas faces expostas do compósito cimentício. Nesta pesquisa, porém, o objeto de estudo foi a Argamassa Reforçada com Fibras de Aço (ARFA), com a intenção de isolar variáveis (como a influência dos agregados graúdos na permeabilidade do compósito) e definir hipóteses simplificadoras como, por exemplo, considerar uma frente de penetração de $\mathrm{Cl}^{-}$uniforme em cada face. 
NUNES, A. C. M.; PIERALISI, R.; BRAGANÇA, M. O. G. P., ATAQUE POR ÍONS CLORETO EM ARGAMASSAS REFORÇADAS COM FIBRAS DE AÇO: INFLUÊNCIA DO TEMPO DE EXPOSIÇÃO E DA ABERTURA DE FISSURA. $4^{\circ}$ Simpósio Paranaense de Patologia das Construções (40 SPPC), artigo 4SPPC141, pp. 370 - 380, 2019. DOI: 10.4322/2526-7248.059

\section{Materiais e métodos}

\subsection{Materiais}

O aglomerante empregado na campanha experimental foi o cimento Portland CPII-F 32, passível de ser utilizado em argamassas armadas e, comumente empregado na região sul do Brasil, além de não possuir adições que modificam o ganho de resistência do compósito nas primeiras idades. As caracterizações química e física desse material foram fornecidas pelo fabricante, e os valores obtidos respeitaram os mínimos de resistência à compressão exigidos pela norma ABNT NBR 16697/2018 [7].

O material utilizado como agregado miúdo neste estudo foi a areia artificial originada da britagem de agregados graúdos, provenientes da pedreira localizada em Mandirituba, região metropolitana de Curitiba. Os ensaios para sua caracterização química e física foram realizados conforme as normativas nacionais vigentes. De acordo com o ensaio de granulometria, o diâmetro máximo característico (DMC) é de $4,8 \mathrm{~mm}$ e, cerca de $88 \%$ dos grãos possuem dimensão acima de $0,15 \mathrm{~mm}$. Além disso, por meio de ensaios físicos descritos na norma ABNT NBR 15577- 4:2018 [8], verificou-se que o material não possui potencial reativo.

A fibra de aço utilizada na pesquisa foi a de modelo DRAMIX 3D 45/30 BL. Na Tabela 1 estão elencadas as especificações técnicas fornecidas pelo fabricante. Microanálises realizadas confirmaram a ausência de qualquer tratamento superficial na fibra e, não detectaram a presença de metais mais resistentes à corrosão, o que poderia aumentar sua durabilidade durante o processo de envelhecimento acelerado. Sendo assim, confirmou-se que a fibra é composta essencialmente por Ferro (Fe) e carbono $(0,8 \%)$. Além disso, não foram encontrados indícios de realização de tratamento térmico no material, pois seus grãos apresentaram formatos angulosos e aspecto não uniforme.

Tabela 1: Características físicas e mecânicas das fibras de aço do tipo DRAMIX® 3D 45/30BL.

\begin{tabular}{ccc}
\hline Característica & Unidade & Valor \\
Comprimento & {$[\mathrm{mm}]$} & 30 \\
Diâmetro & {$[\mathrm{mm}]$} & 0,62 \\
Fator de Forma & {$[-]$} & 45 \\
Resistência a Tração & {$[\mathrm{MPa}]$} & 1270 \\
Módulo de Young & {$[\mathrm{Gpa}]$} & 210 \\
Número de fibras por kg & {$[-]$} & 13331 \\
\hline
\end{tabular}

\subsection{Métodos}

Por se tratar de um material ainda pouco empregado nas misturas de concreto e argamassa no Brasil, realizou-se uma moldagem preliminar de corpos de prova (CPs) com fibras de aço, na qual posteriormente foi embasada a campanha experimental. Os testes basearam-se nas Normas NBR 16541/2016 [9] para o preparo da mistura 
NUNES, A. C. M.; PIERALISI, R.; BRAGANÇA, M. O. G. P., ATAQUE POR ÍONS CLORETO EM ARGAMASSAS REFORÇADAS COM FIBRAS DE AÇO: INFLUÊNCIA DO TEMPO DE EXPOSIÇÃO E DA ABERTURA DE FISSURA. $4^{\circ}$ Simpósio Paranaense de Patologia das Construções (40 SPPC), artigo 4SPPC141, pp. 370 - 380, 2019. DOI: 10.4322/2526-7248.059

e, NBR 13279/2005 [10] para determinação da resistência à tração na flexão dos corpos de prova. De modo geral, as etapas de fabricação das amostras, ensaio de resistência mecânica à tração na flexão e intemperismo artificial foram contempladas na dosagem preliminar, para que se pudesse antecipar possíveis problemas que poderiam ocorrer durante a campanha experimental. Para garantir que as fissuras provocadas no ensaio mecânico se comportassem como o caminho preferencial para a entrada de cloretos, optou-se pelo traço rico de 1:1 (cimento:areia) em massa. Dessa forma, a permeabilidade da argamassa e a presença de vazios não contribuiriam significativamente para o ingresso de íons $\mathrm{Cl}^{-}$no interior do compósito cimentício por meio de difusão iônica. Assim, com a moldagem preliminar foi possível estabelecer os parâmetros de dosagem necessários para a fabricação dos corpos de prova. Além do traço já mencionado, fixou-se a relação a/c em 0,40 e o teor de fibras em $1,5 \%$ em relação ao volume total de argamassa.

Durante a campanha experimental, as amostras foram fabricadas com dimensões de (40x40x160) mm e os procedimentos basearam-se nas normas NBR 16541/2016 [9] para o preparo da mistura e NBR 13279/2005 [10] para a moldagem e a determinação da resistência à tração na flexão.

Na Figura 1 podem ser observados três pontos que foram definidos para a análise da influência dos íons $\mathrm{Cl}^{-}$na resistência à tração do compósito, sendo eles: a ausência de fissuras (amostra íntegra); a abertura de primeira fissura e a fissura de carga máxima. Para a caracterização total do processo corrosivo das fibras de aço estipularam-se 4 idades de exposição, múltiplas de 28 ciclos, sendo elas: 28, 56, 112 e 224 ciclos de exposição.

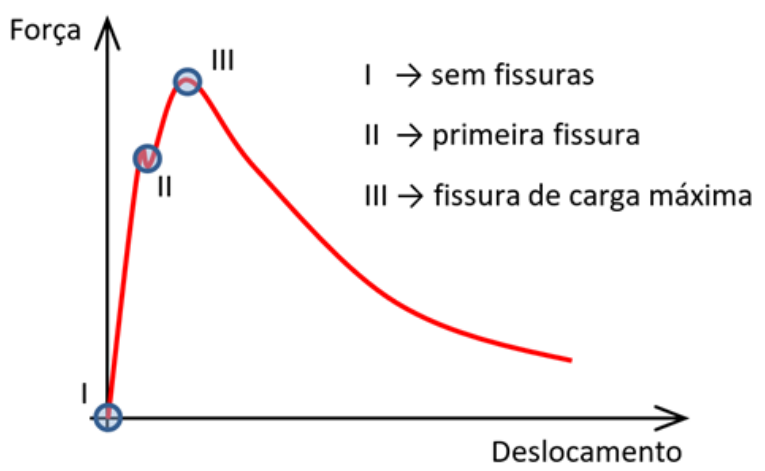

Figura 1: Pontos de interesse da curva de resistência à tração na flexão do compósito.

Durante o estudo foram fabricados 9 corpos de prova por ponto, para cada idade de análise. Isso deve-se a impossibilidade de controlar a disposição das fibras no interior do compósito, e a consequente variabilidade da resistência à tração obtida nos ensaios mecânicos. Essa variação na disposição do material dentro da mistura é uma característica intrínseca às fibras de aço, conforme desmonstrado em estudos anteriores [11]. Primeiramente os corpos de prova produzidos foram caracterizados quanto a sua resistência à tração na flexão na mesma prensa utilizada na dosagem preliminar, de acordo com a NBR 13279/05 [10], objetivando a avaliação da estabilidade e desempenho pós-fissuração do compósito. 
NUNES, A. C. M.; PIERALISI, R.; BRAGANÇA, M. O. G. P., ATAQUE POR ÍONS CLORETO EM ARGAMASSAS REFORÇADAS COM FIBRAS DE AÇO: INFLUÊNCIA DO TEMPO DE EXPOSIÇÃO E DA ABERTURA DE FISSURA. $4^{\circ}$ Simpósio Paranaense de Patologia das Construções (40 SPPC), artigo 4SPPC141, pp. 370 - 380, 2019. DOI: 10.4322/2526-7248.059

As amostras foram divididas em 12 grupos. Os CPs do grupo referência foram caracterizados quanto a sua resistência à tração na flexão e seu comportamento de resistência pós-pico aos 28 dias sem exposição. Em seguida, foi realizado o ensaio de quatro grupos (um para cada idade de exposição) para a abertura da primeira fissura. Esse patamar é caracterizado pelo fim da resistência à tração da argamassa e início da atuação da fibra, que impede a ruptura completa do compósito. Após, outros quatro grupos foram submetidos ao mesmo procedimento, porém, para a obtenção de fissuras de carga máxima. Estudos convergem para a existência de uma abertura de fissura crítica, em torno de $0,2 \mathrm{~mm}$, até onde a corrosão da fibra é limitada e a integridade estrutural do CRFA pode ser assegurada mesmo em exposições prolongadas [12]. Diante disso, nenhuma das fissuras resultantes da flexão das amostras foi menor que $0,2 \mathrm{~mm}$. Para a caracterização do primeiro ponto de interesse (sem abertura de fissuras) as amostras de outros três grupos foram submetidas primeiramente à câmara de névoa salina, e somente após o fim das idades de exposição os corpos de prova foram levados à ruptura completa no ensaio de tração na flexão.

\subsubsection{Câmara de intemperismo artificial}

Posteriormente à cura, os CPs foram divididos em dois grupos para exposição em câmara úmida e em câmara de intemperismo artificial. Foram escolhidas três amostras de cada abertura de fissura para exposição em câmara úmida, com Umidade Relativa (U.R.) maior que $95 \%$ e temperatura de $22{ }^{\circ} \mathrm{C}$. O objetivo dessa exposição foi a comparação da estabilidade e do comportamento pós-pico das amostras expostas nas duas câmaras, ao final das etapas da campanha principal. As amostras acondicionadas sob condições de intemperismo artificial foram submetidas a ciclos de molhagem e secagem em câmara de névoa salina modelo BASS USX6000/2010-CíCLICO. No interior da câmara os CPs foram submetidos a ciclos de molhagem e secagem durante $24 \mathrm{~h}$, das quais $8 \mathrm{~h}$ eram de molhagem por névoa salina com concentração de $5 \%$ de $\mathrm{NaCl}$ em temperatura de $40{ }^{\circ} \mathrm{C}$, e 16 h de secagem a 25 ํ. Dessa forma, um ciclo completo na câmara equivaleu a um dia de exposição.

\subsection{2 Área superficial de machas de corrosão em diferentes idades}

O aparecimento de manchas de corrosão na superfície de elementos de concreto se constitui como uma desvantagem estética da aplicação do material. Tais manchas prejudicam o acabamento superficial dos elementos, podendo gerar desconforto aos usuários e, em um caso extremo, podem conduzir ao Estado Limite de Serviço (ELS) da estrutura. Nesse sentido, foi realizado o acompanhamento fotográfico do aparecimento de manchas de corrosão superficial nos CPs, objetivando correlacionar a existência de maiores manchas em amostras com maiores fissuras. O procedimento adotado foi simplificado, e visando a melhor comparação entre as idades de exposição, as amostras foram fotografadas a partir de uma mesma distância e no mesmo ambiente, a fim de minimizar os efeitos da diferença de luminosidade.

\section{Resultados e discussões}

As amostras foram separadas de acordo com três pontos de interesse, conforme já detalhado. Todos eles foram submetidos ao ensaio de tração na flexão após os períodos de exposição, e posteriormente analisaram-se os resultados em comparação às amostras fletidas sem exposição alguma. Os corpos de prova sem 
NUNES, A. C. M.; PIERALISI, R.; BRAGANÇA, M. O. G. P., ATAQUE POR ÍONS CLORETO EM ARGAMASSAS REFORÇADAS COM FIBRAS DE AÇO: INFLUÊNCIA DO TEMPO DE EXPOSIÇÃO E DA ABERTURA DE FISSURA. $4^{\circ}$ Simpósio Paranaense de Patologia das Construções (40 SPPC), artigo 4SPPC141, pp. 370 - 380, 2019. DOI: 10.4322/2526-7248.059

abertura de fissura, separados de acordo com as idades de 28, 56 e 112 ciclos, foram submetidos ao ensaio de tração na flexão ao fim dos períodos de exposição e, de modo geral, apresentaram comportamento semelhante à curva de referência, como é mostrado na Figura 2.

Por conta da dificuldade em assegurar a orientação das fibras numa direção preferencial durante a moldagem, consequência inerente do uso de fibras, observouse um alto desvio-padrão na carga de pico em todas as curvas analisadas (Fig. 2-a). Esse fato impossibilitou a análise da influência da corrosão na carga máxima de tração na flexão do compósito, uma vez que todas as curvas analisadas são curvas médias, geradas a partir de 9 CPs em cada idade, para cada ponto de interesse. Assim, realizou-se a análise no ramo pós-pico. Para isso, foram unitarizadas as cargas máximas de cada curva, e o deslocamento foi contabilizado a partir da carga de pico. Esse refinamento possibilitou a análise mais detalhada do ramo pós-pico das curvas, como mostrado na Figura 2-b, onde foram observadas resistências muito próximas àquelas apresentadas pelas amostras sem nenhum tipo de exposição.
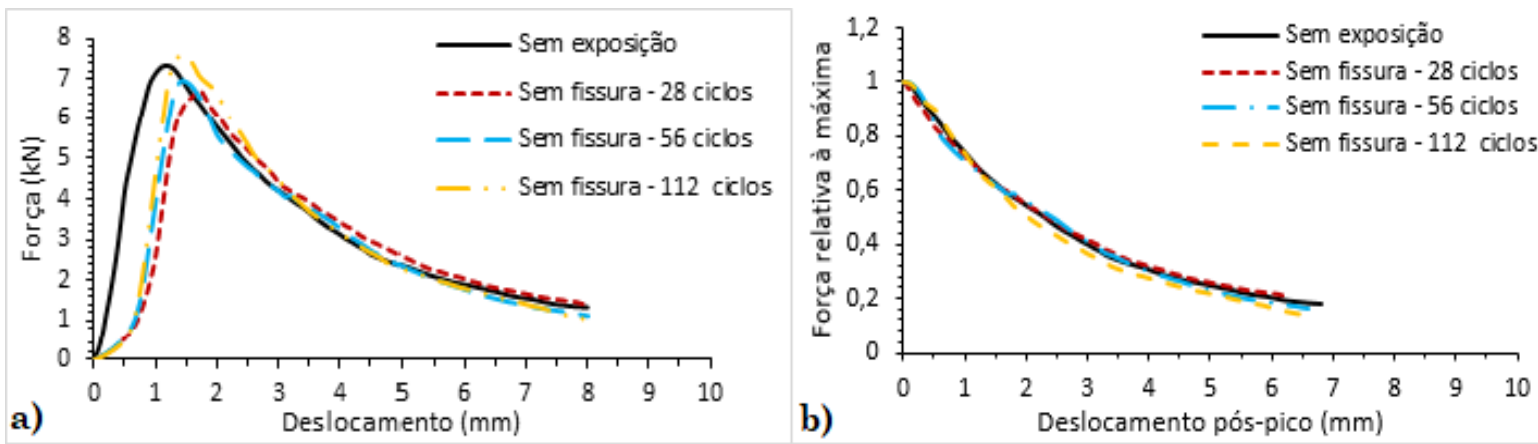

Figura 2: Curvas de resistência à tração na flexão dos corpos de prova sem fissura (a); análise unitária da resistência pós-pico dos corpos de prova de sem fissura (b).

Os resultados apresentados indicaram que não houve influência do ambiente salino na resistência pós pico das amostras sem que haja caminhos preferenciais para a entrada dos íons $\mathrm{Cl}^{-}$para o período de análise. Ou seja, é necessária a existência de porosidade elevada ou fissuras na matriz cimentícia, que promovessem a entrada dos agentes deletérios e, consequentemente, causassem a formação de produtos de corrosão nas fibras de aço. No que se refere às manchas de corrosão, de acordo com a Figura 3, após 112 ciclos de exposição, houveram sinais de corrosão apenas em pontos onde há extremidades de fibras de aço.

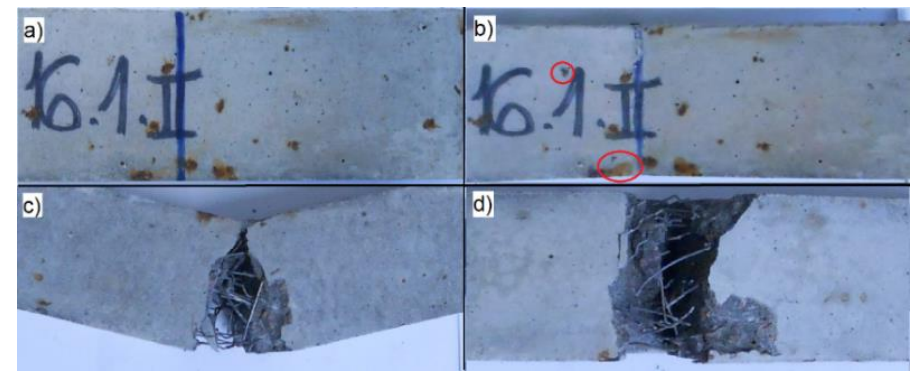

Figura 3: Corpos de prova sem fissura após 112 ciclos de exposição (a); face I após a ruptura aos 112 dias (b); face II após a ruptura aos 112 dias (c); face III após a ruptura aos 112 dias $(d)$. 
NUNES, A. C. M.; PIERALISI, R.; BRAGANÇA, M. O. G. P., ATAQUE POR ÍONS CLORETO EM ARGAMASSAS REFORÇADAS COM FIBRAS DE AÇO: INFLUÊNCIA DO TEMPO DE EXPOSIÇÃO E DA ABERTURA DE FISSURA. $4^{\circ}$ Simpósio Paranaense de Patologia das Construções (40 SPPC), artigo 4SPPC141, pp. 370 - 380, 2019. DOI: 10.4322/2526-7248.059

Além disso, conforme mostrado na Figura 3-d, as fibras que se encontravam no interior das amostras e totalmente envoltas pela matriz cimentícia estavam em perfeito estado após a ruptura, sem nenhum sinal de degradação aparente.

Os corpos de prova submetidos à abertura de $1^{\text {a }}$ fissura nas idades de 28, 56, 112 e 224 ciclos obtiveram, de modo geral, comportamento de melhoramento da resistência (Fig. 4-e). Ao analisar o ramo pós-pico, observou-se o comportamento de melhora da resistência à tração, em comparação à curva de referência, até a idade de 56 ciclos de exposição. Esse comportamento de melhora foi observado também em estudos anteriores [13]. De modo geral, o produto de corrosão formado durante os ciclos de exposição e depositado no entorno das fibras auxiliou no incremento da resistência ao arrancamento das fibras de aço. Com isso, é necessária maior força para a ruptura da interface fibra-matriz e, consequentemente, do corpo de prova. No entanto, a tendência é que essa resistência diminua conforme ocorra a perda de seção resistente da fibra, o que pode ser sugerido pelas curvas de 112 e 224 ciclos de exposição, conforme mostrado na Figura 4-e. Neste gráfico já se demonstra, por parte das últimas idades, comportamento menos resistente em comparação com as idades de 28 e 56 ciclos.
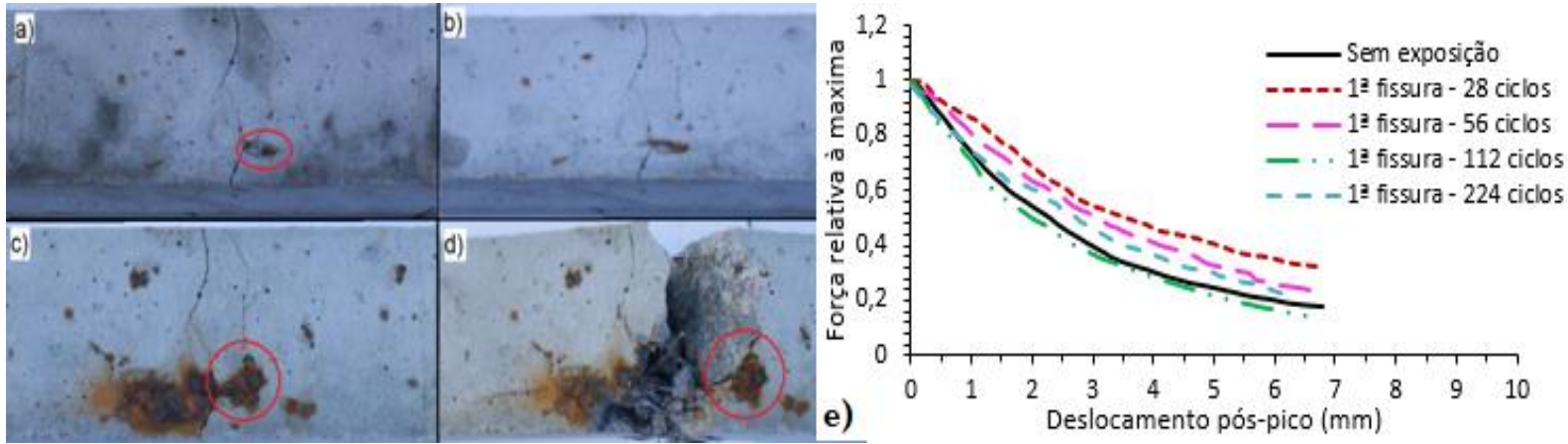

Figura 4: Corpos de prova com abertura de primeira fissura após 8 ciclos de exposição (a); 16 ciclos de exposição (b); 224 ciclos de exposição (c); após a ruptura aos 224 dias (d); gráfico unitário da resistência pós pico para os corpos de prova submetidos à abertura de $1 \stackrel{a}{a}$ fissura.

A diminuição do comportamento resistente, em comparação às primeiras idades, sugere a possível existência de uma idade de saturação da camada resistente fornecida pelos produtos de corrosão e, que esta seja próxima ao período de 112 ciclos. Isso pode indicar o início do processo de perda de resistência das fibras em detrimento do ganho de ancoragem antes fornecido pelos produtos de corrosão.

De acordo com o mecanismo de corrosão por cloretos em armaduras, num primeiro momento há a formação de óxidos estáveis, passivos e compactos, característicos do período de iniciação da difusão dos íons agressivos, correspondente à entrada de cloretos no compósito cimentício. A medida que os íons $\mathrm{Cl}^{-}$chegam às armaduras, as reações com os óxidos presentes formam oxi-hidróxidos que depositam-se em camadas mais frágeis, de fácil desagregação, caracterizando o período de propagação da difusão de cloretos [14]. Nesse sentido, o comportamento observado 
NUNES, A. C. M.; PIERALISI, R.; BRAGANÇA, M. O. G. P., ATAQUE POR ÍONS CLORETO EM ARGAMASSAS REFORÇADAS COM FIBRAS DE AÇO: INFLUÊNCIA DO TEMPO DE EXPOSIÇÃO E DA ABERTURA DE FISSURA. $4^{\circ}$ Simpósio Paranaense de Patologia das Construções (40 SPPC), artigo 4SPPC141, pp. 370 - 380, 2019. DOI: 10.4322/2526-7248.059

nos resultados de corrosão das fibras pode ser análogo ao que é observado em armaduras. Ou seja, a diminuição de resistência pós-pico pode estar relacionada ao período de propagação de íons $\mathrm{Cl}^{-}$, quando existe a formação de hidróxidos com menor resistência que depositam-se em camadas frágeis ao redor do aço.

No que se refere à área de exsudação dos óxidos de ferro, os CPs expostos durante 224 ciclos apresentaram manchas severas, conforme mostrado na Figura 4-c. Os primeiros ciclos de exposição apresentaram poucas manchas, apenas em locais onde havia exposição de fibras de aço. No entanto, ao analisar as partes c-d da Figura 4, verificou-se que houve o aumento progressivo das manchas de corrosão à medida que se aumentou o período de exposição. As fibras localizadas na face da amostra encontravam-se totalmente corroídas após os 224 ciclos. Nesse sentido, assim como ocorre no período de propagação da difusão de cloretos, quanto maior o tempo de exposição, maior a difusão de produtos e, consequentemente, mais frequentes as manifestações patológicas.

Contudo, percebeu-se, que houve a conservação do bom aspecto das fibras contidas no interior do corpo de prova. Uma hipótese para a explicação de tal fato é que, a deposição de produtos de corrosão no entorno das fibras funciona como uma barreira física para a entrada de agentes deletérios, uma vez que diminuem o espaço existente na abertura da fissura, dificultando assim, o transporte dos íons $\mathrm{Cl}^{-}$para o interior do compósito.

Em relação aos corpos de prova submetidos à abertura de fissura de carga máxima verificou-se uma alta quantidade de produto de corrosão depositado na região da fissura de carga máxima, conforme mostrado na Figura 5 (a à d). Em comparação às amostras com abertura de primeira fissura, nas quais o aparecimento de manchas foi mais discreto, os corpos de prova com fissura de carga máxima mostraram significativo grau de deterioração das fibras de aço em uma das faces do compósito. Isso pode ser explicado devido à maior abertura de fissura encontrada nos corpos de prova com fissura de carga máxima. Consequentemente, a área de fibra exposta foi maior, facilitando a deposição de maior quantidade de produtos de corrosão.
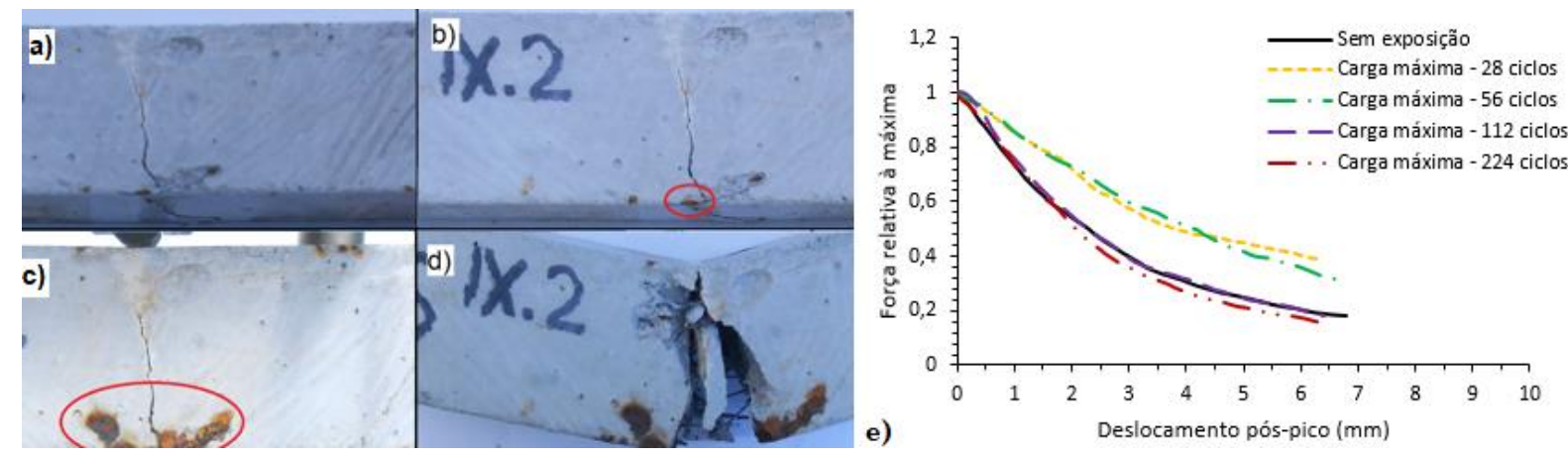

Figura 5: Corpos de prova com fissura de carga máxima após 8 ciclos de exposição (a); 16 ciclos de exposição (b); 224 ciclos de exposição (c); após a ruptura aos 224 dias (d); gráfico unitário da resistência pós-pico para os corpos de prova com fissura de carga máxima (e). 
NUNES, A. C. M.; PIERALISI, R.; BRAGANÇA, M. O. G. P., ATAQUE POR ÍONS CLORETO EM ARGAMASSAS REFORÇADAS COM FIBRAS DE AÇO: INFLUÊNCIA DO TEMPO DE EXPOSIÇÃO E DA ABERTURA DE FISSURA. $4^{\circ}$ Simpósio Paranaense de Patologia das Construções (40 SPPC), artigo 4SPPC141, pp. 370 - 380, 2019. DOI: 10.4322/2526-7248.059

Esse resultado corroborou com os resultados de resistência à tração na flexão, nos quais a partir do $112^{\circ}$ ciclo de exposição há redução da resistência pós-pico. De acordo com a Figura 5-d, é possível notar a perda de seção transversal e, consequentemente de resistência por parte das fibras mais expostas.

As curvas relacionadas à resistência à tração na flexão, mostradas na Figura 5-e confirmam a hipótese levantada durante a discussão de resultados das amostras de abertura de primeira fissura: há a ocorrência da saturação da camada de resistência a partir da idade de 112 ciclos de exposição. O comportamento, anteriormente observado nas curvas de tração na flexão para amostras com abertura de primeira fissura, é mais evidente nos corpos de prova com fissura de carga máxima. Houve o incremento da resistência pós pico devido à maior rugosidade proporcionada pela adesão dos produtos de corrosão no entorno das fibras de aço. Entretanto, esse comportamento foi observado apenas nas duas primeiras idades (Fig. 5-e).

As curvas das amostras expostas por 112 e 224 ciclos mostraram a redução desse aumento de resistência e obtiveram comportamento semelhante à curva sem exposição. Isso pode indicar, possivelmente que, a quantidade de produto de corrosão formado nessas idades já é suficiente para provocar a diminuição da seção resistente das fibras de aço, e esse comportamento é mais significativo para a resistência pós-pico do que a maior rugosidade proporcionada pela formação dos produtos de corrosão. Além disso, conforme já discutido nos resultados das amostras com abertura de primeira fissura, esse comportamento de queda de resistência pode ser análogo ao que ocorre em armaduras convencionais no período de propagação da difusão de cloretos em compósitos cimentícios.

No que se refere ao comportamento em câmara úmida, analisando especificamente o caso de abertura de 1ํ fissura, não foi possível observar diferença significativa no comportamento de resistência à tração na flexão para a idade de 224 ciclos de exposição em relação às amostras sem nenhum tipo de exposição, conforme apresentado na Figura 6.

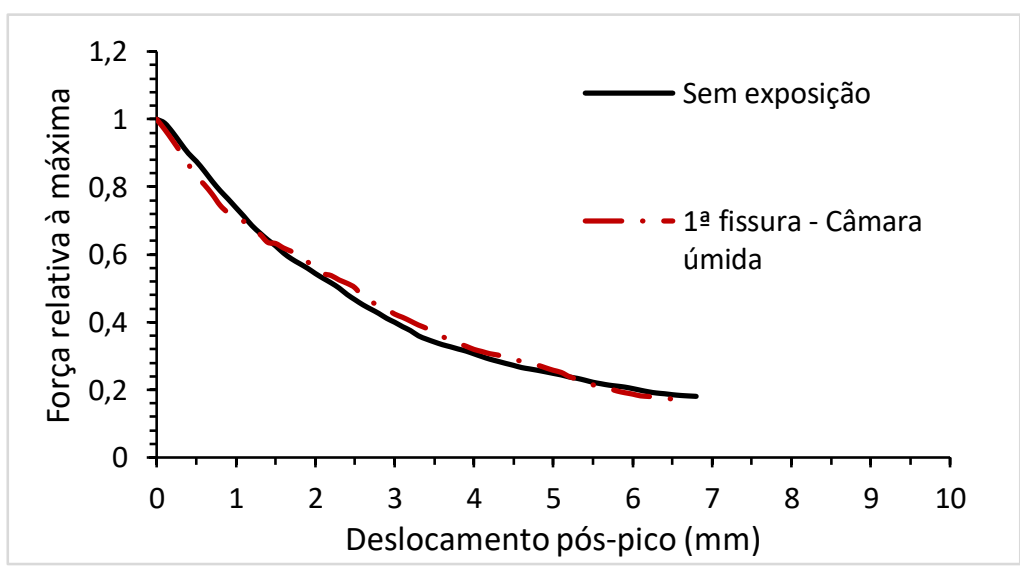

Figura 6: Gráfico unitário da resistência pós pico para os corpos de prova com abertura de 1a fissura em câmara de névoa salina e câmara úmida por 224 ciclos. 
NUNES, A. C. M.; PIERALISI, R.; BRAGANÇA, M. O. G. P., ATAQUE POR ÍONS CLORETO EM ARGAMASSAS REFORÇADAS COM FIBRAS DE AÇO: INFLUÊNCIA DO TEMPO DE EXPOSIÇÃO E DA ABERTURA DE FISSURA. $4^{\circ}$ Simpósio Paranaense de Patologia das Construções (40 SPPC), artigo 4SPPC141, pp. 370 - 380, 2019. DOI: 10.4322/2526-7248.059

De acordo com a Figura 6, é possível observar que não houve ganho de resistência significativo devido à hidratação do cimento por parte das amostras que foram alocadas em câmara úmida, uma vez que o comportamento pós pico foi semelhante ao apresentado pelos corpos de prova do grupo de referência. A continuidade da hidratação em câmara poderia contribuir para o aumento da resistência mecânica do compósito. Contudo, não foi verificada influência de uma possível hidratação tardia no comportamento pós pico dos corpos de prova expostos em câmara úmida.

\section{Conclusões}

A partir dos resultados obtidos foi possível concluir que a cinética de corrosão das fibras de aço pode ser caracterizada por duas fases. A primeira se refere ao incremento da resistência pós-pico, ocasionada pelo aumento da rugosidade na interface entre a fibra e a matriz cimentícia, devido à adesão dos produtos de corrosão no entorno das fibras de aço. Nesse sentido, essa primeira fase pode ser entendida como análoga ao processo de iniciação da difusão de cloretos, caracterizada por óxidos compactos e passivos. Ao longo das idades, é possível que ocorra a segunda fase, na qual a perda de resistência, devido à redução da seção resistente das fibras, pode ser mais significativa do que o incremento de aderência fornecido pela deposição dos óxidos. Essa etapa, por sua vez, pode ser caracterizada como análoga ao período de propagação da difusão de cloretos em compósitos cimentícios, no qual há a formação de produtos de baixa aderência. Neste estudo foi possível verificar a ocorrência total da primeira fase e início da segunda fase, uma vez que a partir do $112^{\circ}$ ciclo de exposição notou-se redução do incremento da resistência pós pico. Porém, os 224 ciclos de exposição também não foram suficientes para caracterizar completamente o processo de corrosão.

\section{Agradecimentos}

Os autores agradecem à infraestrutura e ao apoio em recursos humanos e financiamento ao Lactec, ao Departamento de Construção Civil da Universidade Federal do Paraná, à Itambé Cimentos e à ArcelorMittal Brasil.

\section{Referências}

[1] ASSOCIAÇÃO BRASILEIRA DE NORMAS TÉCNICAS - ABNT (2007). NBR 15530: Fibras de aço para concreto - Especificação. Rio de Janeiro, 2007.

[2] ABRISHAMI, H. H; MITCHELL, D. Influence of steel fibers on tension stiffening. American Concrete Institute (ACI) - Structural Journal. v. 94, p. 769-776, 1997.

[3] MANGAT, P. S.; GURUSAMY, K. Chloride diffusion in steel fibre reinforced concrete containing PFA. Cement and Concrete Research. v. 17 (4), p. 640-650, 1987.

[4] FIGUEIREDO, A. D. Concreto reforçado com fibras. Tese (Livre Docência), Universidade de São Paulo, São Paulo, 2011. 
NUNES, A. C. M.; PIERALISI, R.; BRAGANÇA, M. O. G. P., ATAQUE POR ÍONS CLORETO EM ARGAMASSAS REFORÇADAS COM FIBRAS DE AÇO: INFLUÊNCIA DO TEMPO DE EXPOSIÇÃO E DA ABERTURA DE FISSURA. $4^{\circ}$ Simpósio Paranaense de Patologia das Construções (40 SPPC), artigo 4SPPC141, pp. 370 - 380, 2019. DOI: 10.4322/2526-7248.059

[5] BLAGOJEVIC, A; KOLEVA, D. A; WALRAVEN, J. C. The influence of cracks on chloride-induced corrosion of reinforced concrete structures - development of the experimental set-up. Young Researchers' Forum II: Construction Materials. Departamento de Engenharia Civil e Geociências, p. 159-164, Londres, Reino Unido, 2014.

[6] MESON, M. V.; MICHEL, A.; SOLGAARD, A.; FISCHER, G.; EDVARDSEN, C.; SKOVHUS, T. L. Corrosion resistance of steel fibre reinforced concrete - A literature review. Cement and Concrete Research. v. 103, p. 1-20, 2016.

[7] ABNT (2018). NBR 16697: Cimento Portland-Requisitos. Rio de Janeiro, 2018.

[8] ABNT (2018). NBR 15577-4: Agregados - Reatividade Álcali-agregado. Parte 4: Determinação da expansão em barras de argamassa pelo método acelerado. Rio de Janeiro, 2018.

[9] ABNT (2016). NBR 16541: Argamassa para assentamento e revestimento de paredes e tetos - Preparo da mistura para a realização de ensaios. Rio de Janeiro, 2016.

[10] ABNT (2005). NBR 13279: Argamassa para assentamento e revestimento de paredes e tetos - Determinação da resistência à tração na flexão e à compressão. Rio de Janeiro, 2005.

[11] CAVALARO, S. H. P.; AGUADO, A. Intrinsic scatter of FRC: an alternative philosophy to estimate characteristic value. Materials and Structures. v 48 (11), p. 3537-3555, 2015.

[12] TRAN, N. T; PYO, S.; KIM, D. J. Corrosion resistance of strain-hardening steelfiber-reinforced cementitious composites. Cement and Concrete Composites. v. 63, p. 17-29, 2015.

[13] FRAZÃO, C.; BARROS, J.; CAMÕES, A.; ALVES, A. C.; ROCHA, L. Corrosion effects on pullout behavior of hooked steel fibers in self-compacting concrete. Cement and Concrete Research. p. 112-122, 2016.

[14] VEDALAKSHMI, R.; SARASWATHY, V.; SONG, H. W.; PALANISWAMY, N. Determination of diffusion coefficient of chloride in concrete using Warburg diffusion coefficient. Corrosion Science. p. 1299-1307, 2009. 